\title{
Green Silver Nanoparticles Embedded in Cellulosic Network for Fresh Food Packaging
}

\author{
S. Chaitanya Kumari ${ }^{D}$, P. Naga Padma and K. Anuradha* ${ }^{D}$
}

Department of Microbiology, Bhavan's Vivekananda College of Science, Humanities and Commerce, Sainikpuri, Secunderabad - 500 094, Telangana, India.

\begin{abstract}
The demand for increasing the shelf life of fresh food as well as the need for protecting the food against foodborne infections warrant the demand for increasing the shelf life of fresh food. The incorporation of nanoparticles into the packaging material can enhance the preservation of perishable foods. Silver nanoparticles (AgNPs), in particular, have antibacterial, anti-mold, anti-yeast, and anti-viral activities can be embedded into the biodegradable packaging materials for this purpose. This study focuses on antimicrobial packaging materials for food by mixing the extracts of different plants with silver nitrate and depositing this mixture as a layer on the blotting papers, which are thick sheets of paper made of cellulose. Because the blotting papers are highly absorbent and porous, silver nitrate solution along with the plant extracts can be easily applied and allowed for in situ synthesis of AgNPs. Subsequently, these papers were analyzed and characterized using scanning electron microscopy, transmission electron microscopy, atomic absorption spectroscopy, and energy dispersive X-ray analysis. The coated paper exhibited good antibacterial activity against Escherichia coli and Staphylococcus aureus. Furthermore, the coated paper when used as a packaging material for tomatoes and coriander leaf, the shelf life was extended to about $\mathbf{3 0}$ days and $\mathbf{1 5}$ days respectively. The prepared cost-effective silver packing material can be used in food packaging for various perishable foods.
\end{abstract}

Keywords: Green synthesis, AgNPs coated paper, Antimicrobial activity, Food packaging material

*Correspondence: anuradhapmv@gmail.com

(Received: March 20, 2021; accepted: June 18, 2021)

Citation: Kumari SC, Padma PN, Anuradha K. Green Silver Nanoparticles Embedded in Cellulosic Network for Fresh Food Packaging. J Pure Appl Microbiol. 2021;15(3):1236-1244. doi: 10.22207/JPAM.15.3.13

(C) The Author(s) 2021. Open Access. This article is distributed under the terms of the Creative Commons Attribution 4.0 International License which permits unrestricted use, sharing, distribution, and reproduction in any medium, provided you give appropriate credit to the original author(s) and the source, provide a link to the Creative Commons license, and indicate if changes were made. 


\section{INTRODUCTION}

The perishability of fresh foods is mainly due to the microbial spoilage. Although, a variety of methods such as canning, freezing, drying, etc are used to improve the shelf life of fresh fruits and vegetables, these forms of preservation require a lot of energy and cause the fruits and vegetables to lose their nutritive value. Further, the demand for minimally processed foods (or ready-to-eat foods) is increasing ${ }^{1}$. Therefore, there is a need to find newer ways for increasing the shelf life of fresh and ready-to-eat foods and to develop microbiologically safer foods using environmentally sustainable technologies. Along these lines, we tried to develop food packaging materials with antimicrobial properties.

Strategies to maintain and monitor the release of the smaller quantities of antimicrobial agent from the food packaging material while preserving the quality of foods and increasing their shelf life have been developed ${ }^{2}$. Incorporation of safe, persistent, and broad-spectrum antibacterial agents into the packaging materials is more beneficial, as bacterial contamination is likely to occur on the surface of foods ${ }^{3}$. The most widely used antibacterial agents include organic acids such as acetic acid, benzoic acid, lactic acid, citric acid, and propionic acid ${ }^{4}$. Most of these preservative chemicals have a long history of usage and have received generally recognized as safe (GRAS) status. These chemicals are often used in combination with other antibacterial substances such as nisin or chitosan ${ }^{5}$. However, there is an increasing trend towards preventing the incorporation of artificial chemicals into food or contact materials ${ }^{6}$.

Metals and metal-nanoparticles have a broad range of antimicrobial activity including Gram-positive and Gram-negative bacteria, molds, yeast, and viruses together with enhanced chemical and thermal stability when compared to the organic antibacterial agents. The ease and cost-effectiveness of synthesis of nanoparticles has attracted considerable attention in applications for food packaging ${ }^{7}$. Silver has been recognized since ancient times as an important antibacterial agent for the treatment of diseases and the preservation of food ${ }^{8}$. Besides, silver nanoparticles (AgNPs) are more effective against Gram-negative bacteria than Gram-positive bacteria; because, the
AgNPs can easily penetrate the thin cell wall of Gram-negative bacteria ${ }^{9}$.AgNPs interact with the phosphorus portion of DNA, and interfere with the DNA replication ${ }^{10}$. It is reported that if silver is incorporated within the limits specified by the United States Food and Drug Administration (USFDA), it won't pose any threat to the biological systems ${ }^{11}$. Being a stable metal, silver can be easily incorporated into packaging materials. Further, silver has lesser tendency to make the bacteria resistant when compared to that of antibiotics. AgNPs have multiple uses as antimicrobial agents in the textile industry, water purification systems, medical equipment, cosmetics, and pharmaceutical industries ${ }^{12-14}$. Therefore, silver has been the preferred metal for various applications including the development of food packaging materials. Therefore, AgNPs coated packaging materials can extend the shelf life of fruits and vegetables by preventing the growth of spoilage microorganisms and ultimately slow down the enzymatic process leading to ripening and aging of food materials ${ }^{15}$.

Various physical, chemical, and biological methods are used to prepare AgNPs. Recently, plant extracts have been used for the green synthesis of AgNPs. The bioactive compounds present in the plant extract have a dual role as a reducing agent for $\mathrm{Ag}^{+}$ions and as a stabilizer for the formed AgNPs. Due to the high content of polyphenols, especially anthocyanins, plant extracts have antioxidant activity ${ }^{16-18}$. Microbial polysaccharides along with plant extracts have been used for the green synthesis of AgNPs because of their outstanding biocompatible and biodegradable properties. These polysaccharides are diverse in size and structure that makes them suitable for the reduction and stabilization of $\mathrm{AgNPs}^{19}$. For example, dextran is a polymer of glucose produced by the microorganisms like Weissella confusa, Leuconostoc mesenteroides, and Lactobacillus spp. etc ${ }^{20}$. The AgNPs obtained by green synthesis are considered to be less toxic, safer, easily biodegradable, and cheaper ${ }^{21}$.

The main purpose of the study is to prepare low-cost and more effective food packaging material for perishable foods like tomato, coriander, methi, cherries, papaya, etc. We checked the antibacterial activity of paper sheets embedded with AgNPs on the shelf-life of 
tomatoes and coriander leaf, as model perishable vegetables.

\section{MATERIALS AND METHODS \\ Preparation of plant extract}

Fresh leaves of Ocimum tenuiflorum (Tulasi), Mentha (Mint), Murrayakoenigii (curry leaves), and Aloe vera were collected from local garden and washed with tap water followed by double distilled water to remove any surface contaminants. Approximately $20 \mathrm{gms}$ of air-dried and crushed leaves were mixed with $100 \mathrm{~mL}$ of double-distilled water in a $250 \mathrm{~mL}$ beaker and boiled for about 10-15 min and then cooled and filtered using Whatman No.1 filter paper ${ }^{22}$. The prepared aqueous leaf extract samples were stored at $4^{\circ} \mathrm{C}$ until use.

\section{Coating of AgNPs onto the packing material}

Initially, blotting paper sheets were immersed in the aqueous solution of silver nitrate $(10 \mathrm{mM})$ for one $\mathrm{min}$, followed by rinsing with ethanol (30sec). Later, these sheets were soaked in aqueous leaf extracts separately followed by microbial dextran (5\%) obtained from mutant strain of Weissella confusa and then rinsed in double distilled water for $1 \mathrm{~min}$. For control, blotting sheets were only treated with silver nitrate ${ }^{23}$. The developed sheets were considered as $1^{\text {st }}$ coating and dried overnight at room temperature. Further, the process was repeated to obtain $2^{\text {nd }}$ and $3^{\text {rd }}$ coatings. The obtained AgNPs coated $\left(1^{\text {st }}, 2^{\text {nd }}\right.$ and $\left.3^{\text {rd }}\right)$ blotting paper were stabilized by pressing between two pads.

Characterization of AgNPs coated packing material

The shape and size of the AgNPs coated on the paper were measured using scanning electron microscopy (SEM). For this, a sample with the size of about $1 \mathrm{~cm} \times 1 \mathrm{~cm}$ was cut from the paper surface and observed by the SEM. Also, the AgNPs coated on the blotting paper were scrapped gently and analyzed by transmission electron microscopy. The amount of silver released from the dried coated paper material was also measured on the day 2,4 , and 6 by immersing the paper in distilled water and analyzing the obtained water by atomic absorption spectroscopy. Finally, the amount of silver deposited on the coated paper was characterized by Energy dispersive X-ray analysis (EDX).
Antimicrobial activity of AgNPs coated packing material

The dried AgNPs coated $\left(1^{\text {st }}, 2^{\text {nd }} \& 3^{\text {rd }}\right)$ paper was cut into small discs of $1 \mathrm{~cm}$ in diameter and their antibacterial activity was assessed by using the disc diffusion method ${ }^{24}$ against a Gram-negative bacterium (Escherichia coli) and a Gram-positive bacterium (Staphylococcus aureus). Along with test samples, negative control (paper without AgNPs) and positive control (paper coated with antibiotic-tetracycline) were maintained and inhibition zone was monitored. The experiment was conducted in triplicates.

Shelf-life of vegetables using AgNPs coated packing material

The microbial spoilage and morphological changes of freshly harvested tomatoes and coriander leaves were checked by wrapping them in AgNPs coated paper along with commonly available polythene bag and another was simply exposed to the air separately at room temperature. The experiment was carried for about 30 days.

\section{RESULTS AND DISCUSSION}

The AgNPs obtained by green synthesis are considered as less-toxic (or safer), easily biodegradable and cheaper when compared to those synthesized using chemical methods. For the green synthesis of AgNPs, freshly prepared leaf extracts of Aloe Vera, Curry leaves, Tulasi and Mint were used (Fig. 1).

In the past few decades, a lot of work has been done on the development of packing material with nanoparticles and their action against various microbial species. In the present study, we developed AgNPs coated packing materials using various plant extracts (Fig. 2) and tested their antibacterial properties against $E$. coli and S. aureus. AgNPs synthesized using the Aloe vera extract showed higher antimicrobial efficiency against $E$. coli and S. aureus as 3.2- and 2.9- $\mathrm{mm}$ zone of inhibition, respectively, when compared to AgNPs synthesized using the extracts of Curry leaves, Tulasi and Mint (Fig. 3 and 4). In fact, in all the test samples 2 nd and 3rd coated packing material was good and almost same when compared with $1^{\text {st }}$ coated material. The reason may be that by the end of 1stcoating, the paper got saturated and not able to embed additional AgNPs into its network. Similar observations were 


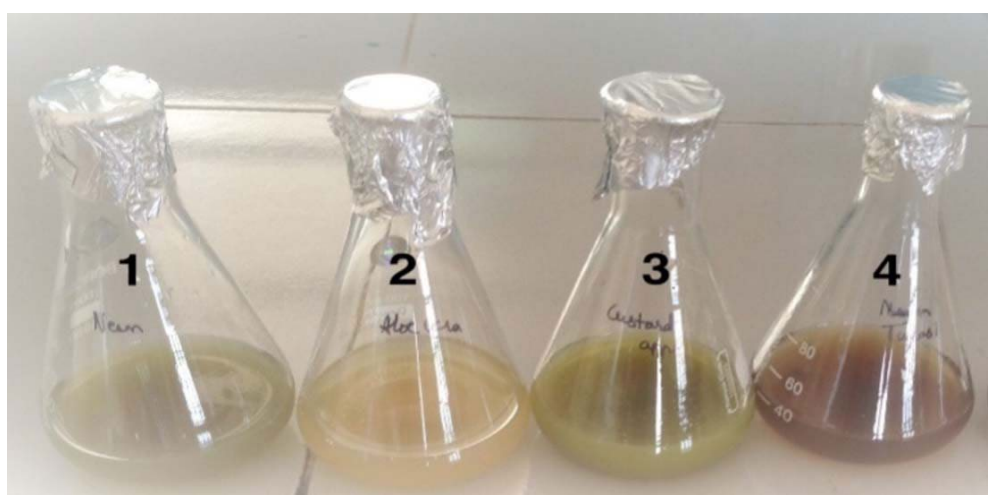

Fig. 1. Extracts of plants (1, Tulasi; 2, Aloe vera; 3, Curry leaves; and 4, Mint).

reported by Hamid ${ }^{25}$. Where the antibacterial activity of AgNPs-coated paper on E. coli and S. aureus is more than the coatings made with antibiotics such as tetracycline and colistin.

We observed an enhanced antibacterial activity with Aloe vera mediated AgNPs coated paper when compared with those of made with other plant extracts. Therefore, we dried Aloe vera mediated AgNPs coated packing material overnight and analysed by AAS to measure the amount of silver released from AgNPs coated paper for about a week. The results showed that amount of silver released from AgNPs coated paper in distilled water as 0.006, 0.01 and 0.010

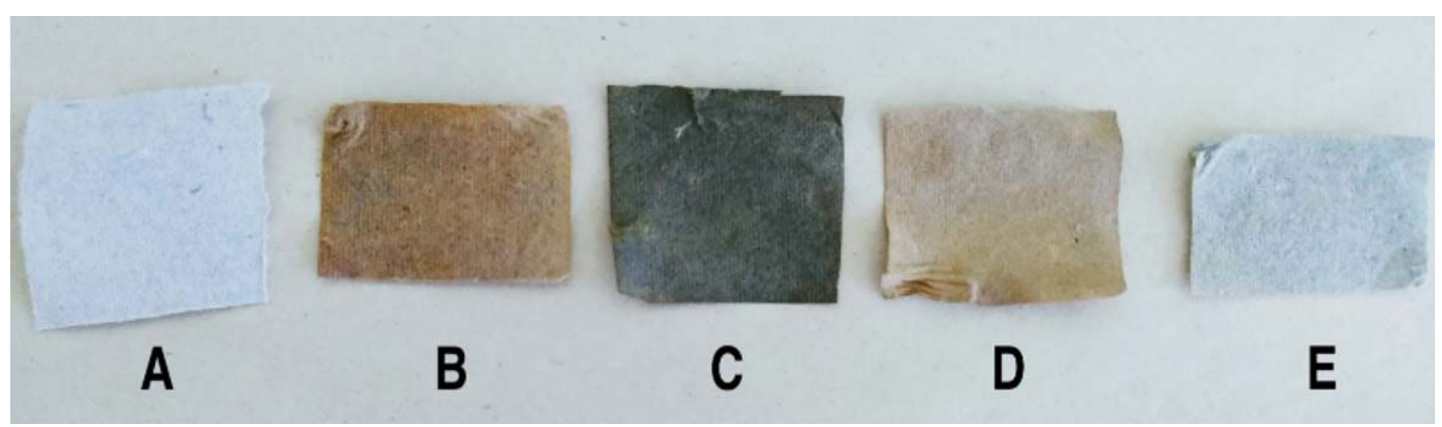

Fig. 2. Blotting papers coated with AgNPs. A- control (without plant extract); B-Tulasi mediated AgNPs; C- Mint mediated AgNPs; D- Aloe vera AgNPs; E- curry leaves mediated AgNPs.

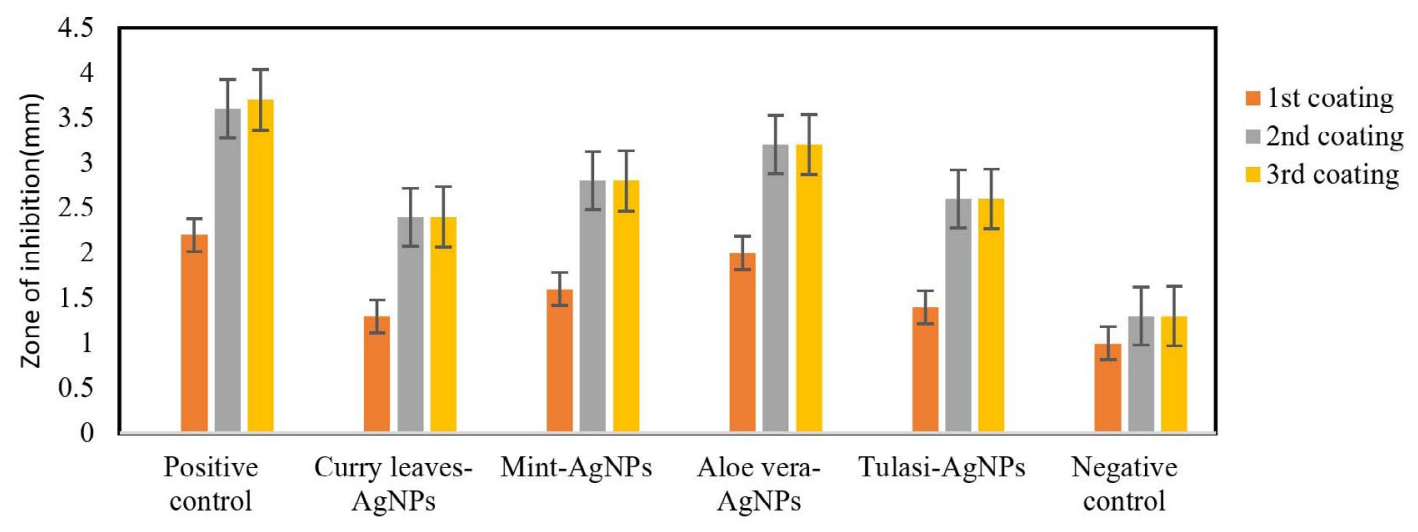

Packing material coated with different AgNPs

Fig. 3. Zone of inhibition by the AgNPs coated packing material against $E$. coli. 


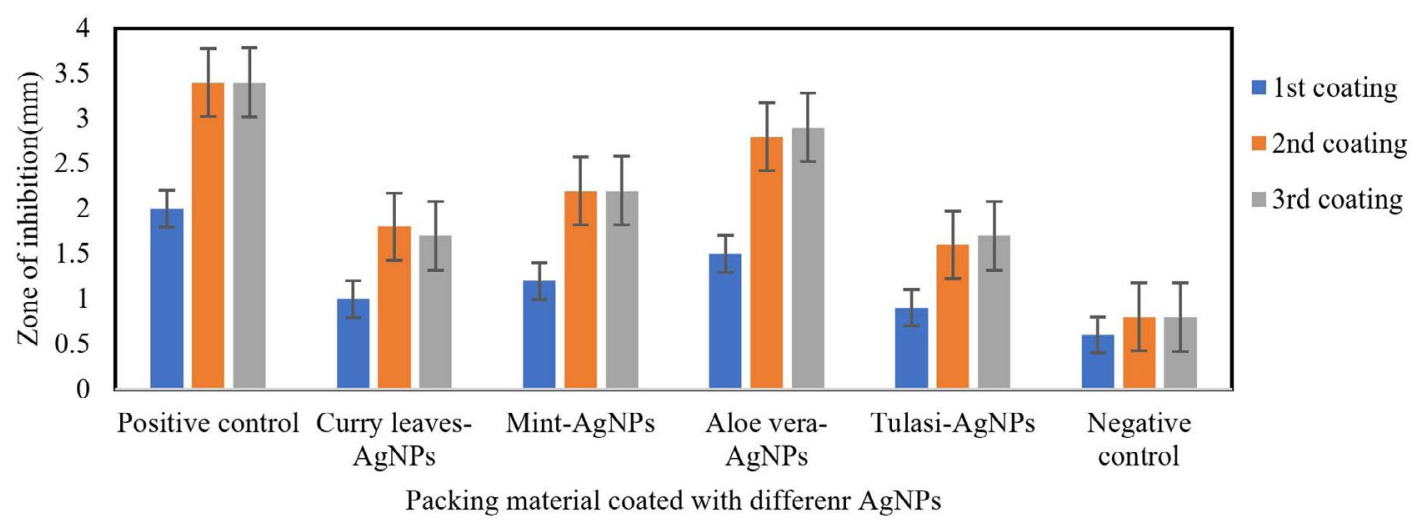

Fig. 4. Zone of inhibition by the AgNPs coated packing material against S. aureus.

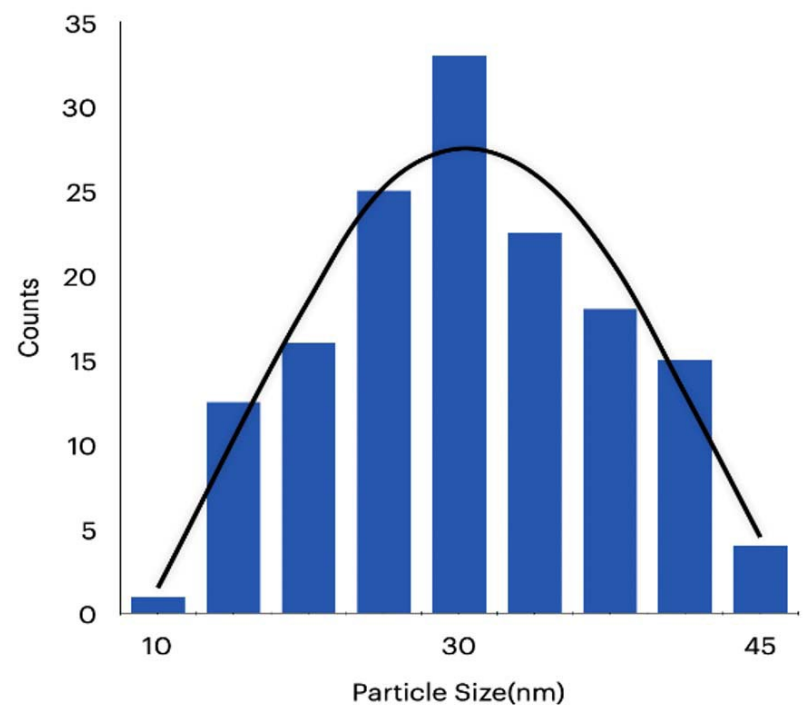

Fig. 5. Size distribution of AgNPs on coated packing material.

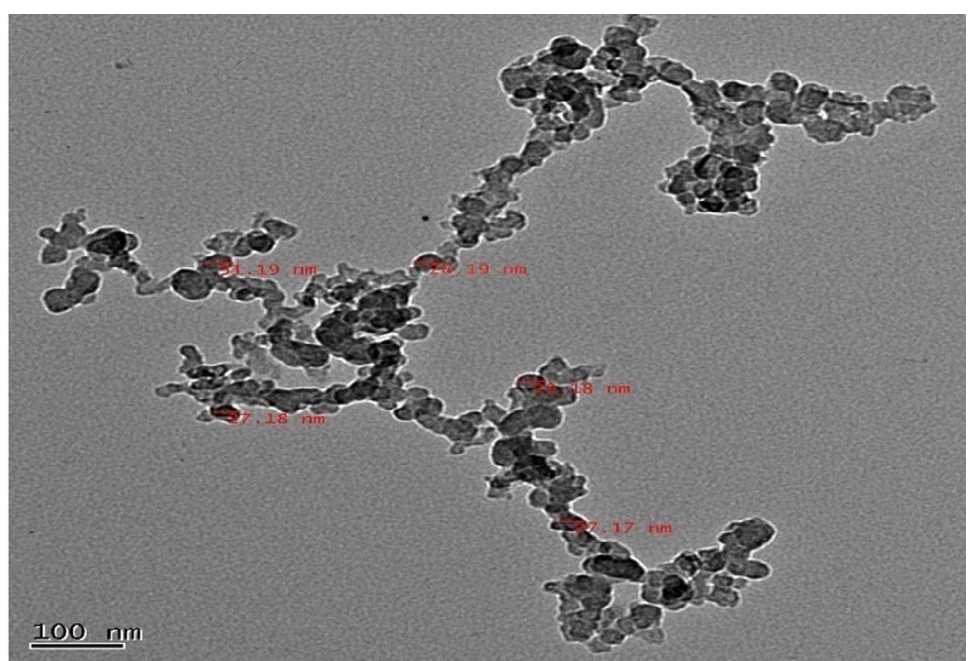

Fig. 6. Transmission electron micrograph of AgNPs coated on paper. 
ppm on $2^{\text {nd }}$ day, $4^{\text {th }}$ day and $6^{\text {th }}$ day respectively (Fig. 5). From the AAS results, it was found that the amount of silver released from AgNPs coated paper was too low; however, it is suitable for use in packing food material.

Apart from the amount of silver released from the packing material one need to take care about how much amount of silver deposited on the packing material as it should be within the USFDA recommended limits for safer use. Hence the Aloe vera mediated AgNPs coated packing material was further analysed by TEM, SEM and EDX (Fig 6,7 , and 8). Aloe vera mediated AgNPs exhibit a typical spherical morphology with the particle diameter was in the range of $27-31 \mathrm{~nm}$ (Fig. 6). The small spherical spots bound to the cellulosic fibres revealed the formation of nanoparticles with an average size of about $20 \mathrm{~nm}$ (Fig. 7). As a result of small sized AgNPs, they can be able to distribute well on the surface of blotting paper that can be ideal for application as a packing material. EDX analysis confirmed the presence of silver on the packing material and also found very less atomic weight percentage, which is non-toxic to humans and safer for its use in food applications (Fig. 8).

Subsequently, we checked for the effect of AgNPs coated packing material on the shelflife of perishable foods such as tomatoes and coriander leaf (Fig. 9). Tomatoes were protected from microbial spoilage and remained fresh until

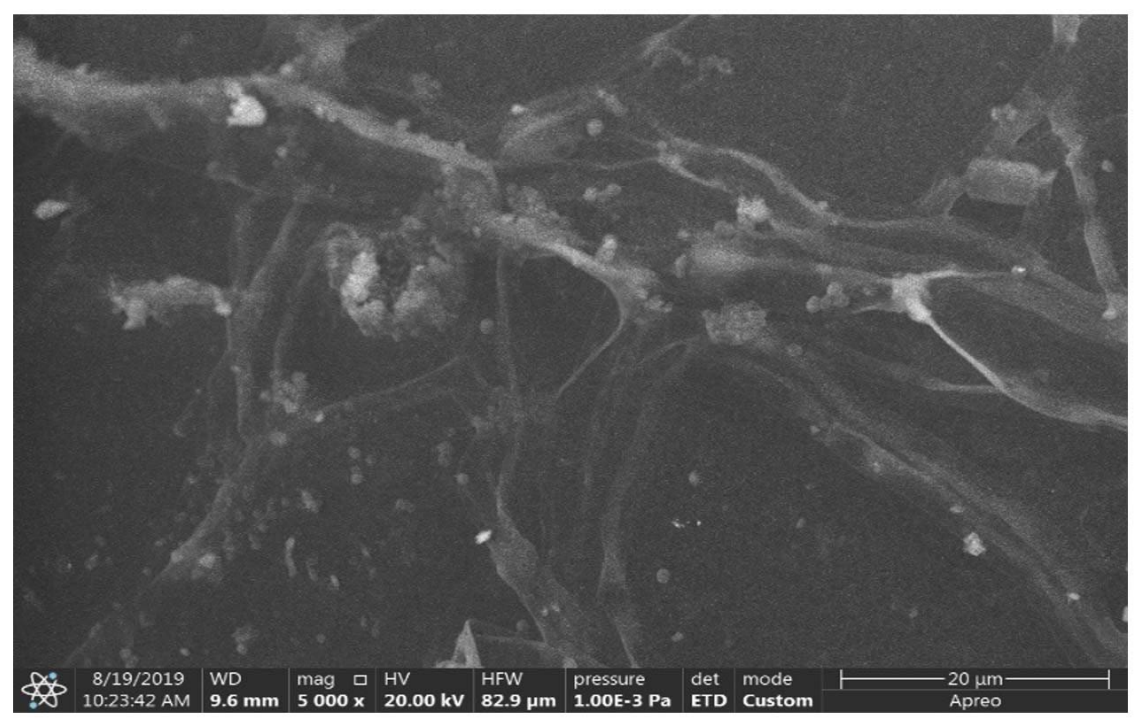

Fig. 7. Scanning electron micrograph of AgNPs coated packing material.

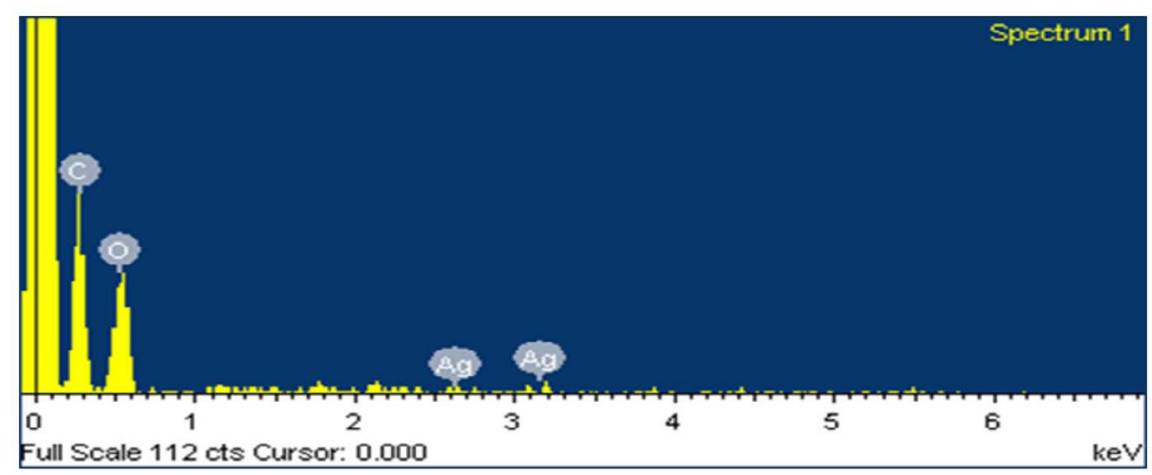

EDX image showing the percentage of silver particles embedded in paper

Fig. 8. EDX analysis of AgNPs coated packing material. 
30 days when stored in AgNPs coated packing material, whereas partial spoilage was noticed along with wrinkles on the surface of tomatoes wrapped in regular polythene bag. This may be due to the lack of proper aeration in polythene bag, which indicates the quality of tomatoes has got reduced but not completely deteriorated unlike tomatoes without any covering exposed directly to the air were started wrinkling within the first week and microbial spoilage was observed within 15 days and was completely deteriorated within 30 days. Similar results were also obtained with preservation of coriander leaves as well but only for 15 days are able to store it freshly compared to tomatoes.

Aloe vera gel contains potentially active component like hydroquinone's that act as a strong reducing agent ${ }^{26}$ which rapidly reduces silver ions resulting in the generation of vast number of silver nuclei and thus reduced growth leading to smaller size of nanoparticles in combination with microbial dextran that acted as a capping agent and increased the stability of AgNPs coated on the paper during the preservation of tomatoes and coriander leaf for about 30 days and 15 days respectively. And also maintained

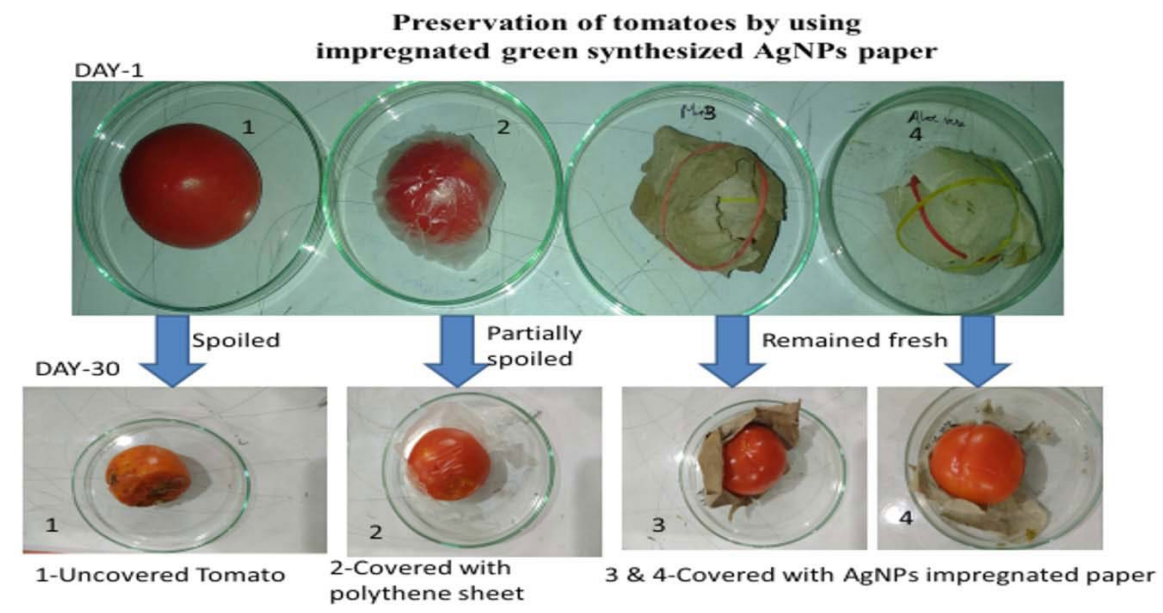

A- Preservation of tomatoes for about 30 days

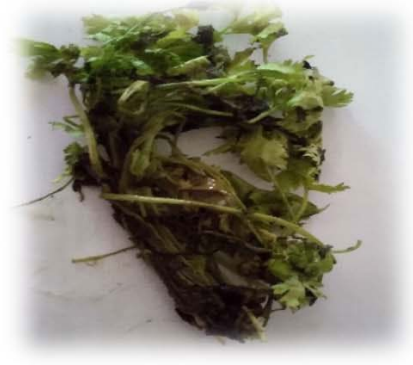

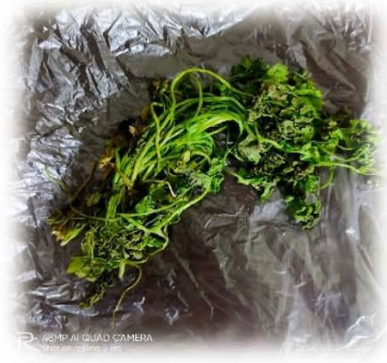

b

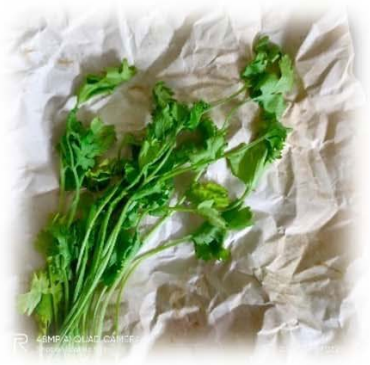

B- Preservation of corainder leaf for about 15 days: a-Stored at Room temperature; $\mathbf{b}$-Wrapped in polythene sheet; c-Wrapped in AgNPs coated packing material

A. Preservation of tomatoes for about 30 days

B. Preservation of corainder leaf for about 15 days: a-Stored at Room temperature; b-Wrapped in polythene sheet; C-Wrapped in AgNPs coated packing material

Fig. 9. Preservation ofperishable food items using AgNPs coated packing material (A\&B) 
optimum humidity over the surface of tomatoes and protected from wrinkling along with microbial attack.

Therefore, toxicity due to high amount of silver in regular commercially available packing material can be prevented by using these developed Aloe vera mediated AgNPs coated packing material having permissible amount of silver as a regular packing material for various perishable food products at least for a period of 30 days. These results were in agreement with those of Emamifar et $\mathrm{al}^{27}$, who reported the inhibition effect of packages impregnated with $\mathrm{Ag}$ and ZnO nanoparticles on Lactobacillus plantarum in orange juice. Recently Beig et $\mathrm{al}^{28}$, developed a low-density polyethylene (LDPE) package films incorporated with $\mathrm{Ag}$, copper oxide (CuO), and zinc oxide $(\mathrm{ZnO})$, and found a reduction in coliform counts of ultra-filtered cheese stored at $4 \pm 0.5^{\circ} \mathrm{C}$ for 4 weeks.

\section{CONCLUSION}

In this study, the silver nanoparticles were coated on blotting paper using various plant extracts along with microbial dextran. The size and amount of silver nanoparticles on paper were studied by SEM, TEM, AAS and EDX. Aloe vera mediated AgNPs-coated paper can be successfully used for inhibiting or reducing Gram-negative $E$. coli and Gram-positive S. aureus. The coated paper can be used as a food packing material to increase the shelf life of perishable food products for atleast 30 days. In addition, this method is carried out at room temperature and consumed no energy; therefore, it is economically suitable.

\section{ACKNOWLEDGMENTS}

The authors are grateful to the management of Bhavans Vivekananda College of Science, Humanities and Commerce, Sainikpuri, Secunderabad and Department of Microbiology, Osmania University, Hyderabad. Thanks to College of technology, Osmania University for providing assistance on analysis.

\section{CONFLICT OF INTEREST}

The authors declare that there is no conflict of interest.

\section{AUTHORS' CONTRIBUTION}

CK, NP and KA designed the experiments. CK drafted the manuscript, compiled information from the literature and designed the figures. KA supervised and reviewed the manuscript.

\section{FUNDING}

None.

\section{DATA AVAILABILITY}

All datasets generated or analysed during this study are included in the manuscript.

\section{ETHICS STATEMENT}

This article does not contain any studies with human participants or animals performed by any of the authors.

\section{REFERENCES}

1. Morris JG. How Safe Is Our Food? Emerg Infect Dis. 2011;17(1):126-128. doi: 10.3201/eid1701.101821

2. Mastromatteo M, Mastromatteo M, Conte A, Del Nobile MA. Advances in controlled release devices for food packaging applications. Trends in Food Science \& Technology. 2010;21(12):591-598. doi: 10.1016/j. tifs.2010.07.010

3. Appendini P, Hotchkiss JH. Review of antimicrobial food packaging. Innov Food Sci Emerg Technol. 2002;3(2):113-126. doi: 10.1016/s14668564(02)00012-7

4. Schirmer BC, Heiberg R, Eie T, et al. A novel packaging method with a dissolving $\mathrm{CO}_{2}$ headspace combined with organic acids prolongs the shelf life of fresh salmon. Int J Food Microbiol. 2009;133(1-2):154-160. doi: 10.1016/j.ijfoodmicro.2009.05.015

5. Campos CA, Gerschenson LN, Flores SK. Development of Edible Films and Coatings with Antimicrobial Activity. Food and Bioprocess Technology. 2010;4(6):849-875. doi: 10.1007/s11947-010-0434-1

6. Cruz-Romero MC, Murphy T, Morris M, Cummins E, Kerry JP. Antimicrobial activity of chitosan, organic acids and nano-sized solubilisates for potential use in smart antimicrobially-active packaging for potential food applications. Food Control. 2013;34(2):393-397. doi: 10.1016/j.foodcont.2013.04.042

7. Benavente J, Garcia ME, Urbano N, et al. Inclusion of silver nanoparticles for improving regenerated cellulose membrane performance and reduction of biofouling. Int J Biol Macromol. 2017;103:758-763. doi: 10.1016/j.ijbiomac.2017.05.133

8. Stanley S. Biological nanoparticles and their influence on organisms. Curr Opin Biotechnol. 2014;28:69-74. doi: 10.1016/j.copbio.2013.11.014

9. Prema P, Thangapandiyan S, Immanuel G. CMC stabilized nano silver synthesis, characterization and its antibacterial and synergistic effect with broad spectrum 
antibiotics. Carbohydrate Polymers. 2017;158:141148. doi: 10.1016/j.carbpol.2016.11.083

10. Chellaram C, Murugaboopathi G, John AA, et al. Significance of Nanotechnology in Food Industry. APCBEE Procedia. 2014;8:109-113. doi: 10.1016/j. apcbee.2014.03.010

11. Food Production Report. Sweden to outlaw bisphenol A in kids packaging but rejects full ban. https://www. foodnavigator.com/Article/2012/04/18/Sweden-tooutlaw-bisphenol-A-in-kids-packaging-but-rejects-fullban/ Accessed 20 April, 2012.

12. Sanjay S. Green Synthesis, Characterization and Applications of Nanoparticles. Safe Nano is Green Gano. 2019:27-36. doi: 10.1016/B978-0-08-1025796.00002-2

13. Arya RG, Kumari M, Gupta N, Kumar A, Chandra R, Nimesh $S$. Green synthesis of silver nanoparticles using Prosopis juliflora bark extract: reaction optimization, antimicrobial and catalytic activities. Artif Cells Nanomed Biotechnol. 2018;46(5):985-993. doi: 10.1186/s11671-018-2731-y

14. Devanesan S, AISalhi MS, Balaji RV, et al. Antimicrobial and Cytotoxicity Effects of Synthesized Silver Nanoparticles from Punica granatum Peel Extract. Nanoscale Res Lett. 2018;13:315. doi: 10.1186/s11671018-2731-y

15. Adepu S, Khandelwal M. Broad-spectrum antimicrobial activity of bacterial cellulose silver nanocomposites with sustained release. Journal of Materials Science. 2017;53(3):1596-1609. doi:10.1007/s10853-017$1638-9$

16. Sivaranjana P, Nagarajan ER, Rajini N, Jawaid M, Rajulu AV. Cellulose nanocomposite films with in situ generated silver nanoparticles using Cassia alata leaf extract as a reducing agent. Int J Biol Macromol. 2017;99:223-232. doi: 10.1016/j.ijbiomac.2017.02.070

17. Arya RG, Kumari M, Sharma N, et al. Catalytic, antibacterial and antibiofilm efficacy of biosynthesised silver nanoparticles using Prosopis juliflora leaf extract along with their wound healing potential. Journal of Photochemistry and Photobiology B: Biology. 2019;190:50-58. doi: 10.1016/j. jphotobiol.2018.11.005

18. Mehra A, Chauhan S, Jain VK, Nagpal S. Nanoparticles of Punicalagin Synthesized from Pomegranate (Punica
Granatum L.) with Enhanced Efficacy Against Human Hepatic Carcinoma Cells. J Clust Sci. 2021. doi: 10.1007/s10876-021-01979-9

19. Kothari D, Das D, Patel S, Goyal A. Dextran and Food Application. Polysaccharides. 2015;735-752. doi: 10.1007/978-3-319-16298-0_66

20. Maina $\mathrm{NH}$, Tenkanen $\mathrm{M}$, Maaheimo $\mathrm{H}$, Juvonen $\mathrm{R}$, Virkki L. NMR spectroscopic analysis of exopolysaccharides produced by Leuconostoc citreum and Weissella confusa. Carbohydrate Research. 2008;343(9):14461455. doi: 10.1016/j.carres.2008.04.012

21. Duncan TV. Applications of nanotechnology in food packaging and food safety: Barrier materials, antimicrobials and sensors. J Colloid Interface Sci. 2011;363(1):1-24. doi: 10.1016/j.jcis.2011.07.017

22. Padma P, Banu S, Kumari S. Studies on Green Synthesis of Copper Nanoparticles Using Punica granatum. Annu Res Rev Biol. 2018;23(1):1-10.doi: 10.9734/ arrb/2018/38894

23. Swensson B, Ek M, Gray DG. In Situ Preparation of Silver Nanoparticles in Paper by Reduction with Alkaline Glucose Solutions. ACS Omega. 2018;3(8):9449-9452. doi: 10.1021/acsomega.8b01199

24. Brown DF, Kothari D. Comparison of antibiotic discs from different sources. J Clin Pathol. 1975;28(10):779783. doi: $10.1136 /$ jcp. 28.10 .779

25. Ghorbani HR. Biological coating of paper using silver nanoparticles. IET Nanobiotechnology. 2014;8(4):263266. doi: 10.1049/iet-nbt.2013.0039

26. Surjushe A, Vasani R, Saple D. Aloe vera: A short review. Indian Journal of Dermatology. 2008;53(4):163-166. doi: 10.4103/0019-5154.44785

27. Emamifar A, Kadivar M, Shahedi M, Solimanian-Zad S. Effect of nanocomposite packaging containing $A G$ and $\mathrm{ZnO}$ on reducing pasteurization temperature of orange juice. Journal of Food Processing and Preservation. 2012; 36(2): 104-112. doi: 10.1111/j.17454549.2011.00558.x

28. Beigmohammadi F, Peighambardoust $\mathrm{SH}$, Hesari J, Damirchi, SA, Peighambardoust, SJ, Khosrowshahi NK. Antibacterial properties of LDPE nanocomposite films in packaging of UF cheese. LWT - Food Science and Technology. 2016;65:106-111. doi: 10.1016/j. Iwt.2015.07.059 